\title{
A UNIVERSIDADE DO FUTURO:
}

Estudos Preliminares Comparados da Renovação das

Universidades de Berlim (Alemanha) e Paraiba (Brasil)

Beind Rabehl

Renato Kilpp

Jurandir Antonio Xavier

Luicia de Filima Almeida Couto'

UM BREVE HISTÓR!CO

A 'idéia' de miversidade, de sua autonomia irrestrita, nunca deixou de transformar-se com a realidade política. Na Alemanha, as universidades estiveram submetidas à politização já no século XIX, enbora esse processo encontre un final transitório em 1933. No Brasil elas já nasceram politizadas. Nas questóes relativas a financianentos, nomeações, admissócs, temas de pesquisa e ensino, normas de exames, concursos públicos e alocação dos estudantes universitários, nestes assuntos da universidade, Estado e economia privada trequientemente tiveram suas participaçóes, sem, no entanto, poder destruir no fundamental sua 'autonomia' e autogestão. A ditadura nacional-socialisia destruiu esta auto-suficiência, intervindo diretamente na miversidade, tornando o ensino e a pesquisa dependentes das exigências da economia de guerra e da ordem interna da di-

1 Dos antores: Bernd Rabehl, Professor da Universidade Livre de Bertim; Renato Kilpp, Professor da IFPB/Campus II; Jurandir A. Xavicr, Professor da UFPB/Campus II; Lricia Couto, Professora da Iniversidade Estadual da Paraíba. 
tadura. As universidades foram levadas às imposiçóes políticas do Estado e o ensino experimentou, através do Ministério da Cultura, a sistemática própria das escolas técnicas superiores, formando determinadas quantidades de especialistas en curtos prazos. Contudo, mesmo nas condições de ditadura, permaneceram 'resíduos' da velha universidade nas respectivas áreas especializadas. Eles tornaranse pontos de partida da 'restauração' da velha universidade na República Federal, que tomou curso só a partir dos anos sessenta, sob pressão da educação em massa c da regulação estatal.

As universidades no Brasil desenvolveram-se a partir de escolas isoladas, religiosas, militares e mesmo civis, de teologia, filosofia, direito, medicina e engenharia, sendo repensadas, sob a ditadura de Vargas, como locais de formação de uma moderna inteligência, que tivesse em mente a perspectiva social de um país industrial, desvinculando-se do provincianismo e dos privilégios das elites tradicionais. Não por acaso as universidades públicas de São Paulo c Rio de Janciro alcançaram proporçóes e qualidade das universidades curopéias ocidentais, que estavam comprometidas com as idéias de autonomia $\mathrm{e}$ autogestão universitárias. Industrialização, alfabetização e modernização exigian, junto aos espccialistas, também uma inteligência, representando uma totalidade social, para a qual as transformaçóes de longo prazo da sociedade trouxessem como resultado a despedida do atraso econômico e das tradiçôes coloniais. Nas condições da ditadura, a universidade foi vista como um meio de desalojar as elites tradicionais e de preparar o terreno para a nova inteligência que - como executiva dos bancos e da indústria, como altos funcionários públicos e produtores culturais, como professores universitários e pesquisadores - fixariam novas condiçōes de trabalho na administração $e$ na economia, influenciando as transformaçóes sociais em curso.

Das universidades, na verdade, vieram as oposiçóes intelectuais à ditadura, mas sua força produtiva como fator de renovação e como elemento de transformaçôes culturais foram apreciados tão significativamente por parte da administração estatal do Presidente Vargas, que os aspectos político-oposicionistas não foram vistos como suficientes para intromissōes governamentais maiores, imobilizadoras do desenvolvimento das universidades. Mesmo em 1968, a ditadura militar se 
engaja na modernização da universidade, mantendo-a consideravelmente independente, tendo-a como instrumento de modernização social e instituindo novas universidades federais ao longo do território nacional. Muito cedo no Brasil, as universidades estiveram submetidas às pressões da politização, caindo na pressão da racionalização ou 'economização' só no ocaso da ditadura militar, a partir de meados dos anos oitenta. A imposição da educação em massa, resultado da demanda social por qualificação intelectual e expressão de mudanças técnicas e econômicas infra-estruturais da sociedade, que alcançaram de forma crescente as universidades brasileiras, acabaran mudando suas funçóes. Aliás, como na Nlcmanha, também aqui acabou se impondo a redução qualitativa da formação universitária em termos de escola profissional, deixando de ser a universidade de massa, local de formação de elites ${ }^{2}$.

\section{A 'SOCIALIZACÃ̃o' DAS UNIVERSIDADES E SUA MASSIFICAÇÃO}

A crescente intelectualização da qualificação do trabalho nas diferentes áreas administrativas, produtivas, culturais e sociais, elevou o fluxo de demandas das universidades na Alemanha e no Brasil. Sua massificação teve conséquiências inediatas para a pesquisa, o ensino $\mathrm{e}$, sobretudo, para as profissóes intelectuais. Uma intelectualização da qualificação do trabalho, no entanto, não foi identificado com definiçóes profissionais precisas nas carreiras acadênicas, de tal maneira que, ao lado das clássicas atividades intelcctuais como professores, engenheiros, médicos, executivos, administradores, etc., surgiu um am-

2 RIBEIRO, D., A Umiversidade Necessária. Săo Paulo, 1969. FERNANDES, F. Edhcaçio e Sociedade mo Brasil, Săo Pat1lo, 1966 e A Unitersidade Brasileira, Săo Paulo, 1979. VAZ, H. de Lima, Calhura e Universidade, Petrópolis, 1966. CUNHA, L. A. A Umiversidad" Temporã, Rio de Janeiro, 1980; A Universidade Chtica, Rio de Janeiro, 1989 e A Universidade Reformanda, Rio de Janeiro, 1989. LIMONGI, R, Mentores e Clientelas de Universidade de São Paulo e A Escola Livre de Sociologia "Política de São Paulo; em MICELLI, S. (Org.), História das Ciências Sociais no Brasil, São Patulo, 1989. RA[3EHL, Bernd, Idece and Realilaet der brasilianischen Universitaet (Mamuskript), Campina Grande, 1990. SCARICABAROZZI, R. A., Universidad, Ciencia y Sociedad en América Lalina, Buenos Nires, 1995. XAVER, J. A., A Universidade no Nordeste, em A Contenponaneidade da Questão Regional, Paraiba, 1992. 
plo espectro de novas atividades intelcotuais potenciais em que cada estudante teria que vir a ser incluído.

As universidades, cm suas atividades de pesquisa e ensino, sob tal pressão social, tiveram que suportar o assalto de jovens que exigiam a formação miversitária sem saber exatamente, porém, como sua futura protissão se definiria. $\Lambda$ ssim, as universidades foram obrigadas, consciente ou inconscientemente, no mínimo, a deixar-se capacitar, a si proprias, às mudanças tecnológicas on comunicativas, dispondo-se aos estudantes de tal mancira que cles tivessem camiuhos de afimação no mercado de trabalho segundo a qualificação adejüirida. Através desta pressão de massa dos estudantes, a universidade experimenton politização e ligaçao indiretas com o mercado de trabalho acadênico. O governo garantiu através de diretrizes básicas o ingresso massivo nas universidades. Entre outras razóes porque aí se tornon, de um lado, lugar e ponto de partida de oposição polítical, de outro, local natural de políticas juvenis, onde, por sua abertura, o desemprego juvenil seria regulado ${ }^{3}$.

Simultancamente, as mudanças na economia e na estrutura social da sociedade refletiram-se nas universidades, impondo a necessidade de uma reação por parte das mesmas. O descnvolvimento industrial na Alemanha nos anos cinqüenta o sessentase no Brasil nos anos setenta, esteve marcado pelos esforços governamentais de regular os investimentos, o emprego, bem cono as políticas monetária, social e salarial nos moldes keynesianos. Claro que tais políticas foram diferentes na Alemanha e no Brasil, adcmais, dependentes das respectivas bases tecnologicas e industriais da economia, apesar dos paralelos existentes. $\Lambda$ contimuidade da internacionalizaçáo das economias nacionais a suas mudanças às novas tecnologias destruíram a capacidade de regulação da intervenção estatal. Esta limitação das medidas governamentais tambén deve ser atribuída à qualidade das novas tecnologias da informática e microdetrônica. Não só a internacionalidade da commicação, intormação e dos movimentos de mercados impuseram-se aos esforços das sondagens nacionais: estas novas téc-

A mova misétial dit edicaçao. 
nicas significaram, ao mesmo tempo, a reestruturação da pesquisa e das relaçōes internas de economia e administração.

Na verdade, o desenvolvinento tecnológico e industrial sempre teve, de alguma forma, correspondencia ao das universidades, agora, porém, sua proximidade com a miversidade e sua referenciação as relaçóes com os trabalhos intelectual e tecnológico passaram a ser obrigatórios. Até então, a organização de ensino e pesquisa nas universidades havia sido expressão de que economia e sociedade queriam saber a força produtiva particular de ciência e educaçáo. Seus custos foram socializados ou foram vistos como bases de investigaçoes e pesquisas especiais que, de algum nodo, se edificaram, nos institutos de pesquisas estatais ou privados e locais de formaçán, sobre tal rendimento universitário. Então, tornou-se importante relacionar fortemente o trabalho universitário nas pesquisas tecnológicas, e também nas definiçoes profissionais das novas atividades conômicas e administrativas. A propria universidade precison refazer sua socialização a privatização para preservar um pedaço de sua independência, tentando superar tendências que aproximavam suas áreas especializadas às escolas técnicas, perdendo contato, entre outras, com os problcmas sociais 4

A NOVA UNIVERSIDADE, A INTERMEDIACÃO DA CIÊNCIA E TECNOLOCIA E A COOPERAÇÃO DIRETA COM OS AGENTES ECONÖMICOS ESTATAIS E PRIVADOS

$\mathrm{Na}$ pesquisa da universidade passa a estar inclúda a determinaçă, isto é, o aclaramento das novas tarefas da universidade relativas às questóes da transferência de tecnologia, de pesquisa e de conbecimento, e aos problemas da privatização parcial de iniciativas, pesqujsas e experiências, voltadas para qualificar c aproximar os estudantes das novas tendências econômicas.

Por conseguinte, na pesquisa, os dois lados da formaça universitária passan então a ser determinados. De um lado, a formação científica e a própria disponibilidade dos estudantes para aquelas pro-

1 A lniversidade no centro de novis tartefas c atividades. 
tissôes que ainda não se tornaram claramente estabelecidas nos mercados, isto é, nos setores dos serviços, do comércio e da produção. De outro lado, a transferência da pesquisa e do conhecimento aplicado na direção das pequenas e médias empresas, via pesquisas universitárias.

Aqui, o ponto de partida da reflexáo é o conceito de inovação. Ele adquire um valor central, porque o lado material das inovaçoes tecnológicas deve ser considerado tanto quanto os pressupostos sociais do aproveitamento tecnológico. Com isso, o desenvolvimento técnico mundial ć incorporado referencialmente às condiçóes sociais, político-educacionais e institucionais, as quais absorvem e traduzem tal desenvolvimento. (O tracasso dos programas de regulação nacional motivam cada govcrno a se posicionar em relação às inovaçóes técnicas, para com isso poder decidir os incentivos à elevação da capacidade de concorrência da jndústria e da produção da nação, relativamente às outras, procurando garantir, com isso, a sobrevivência nas associaçôes industriais e no mercado comum (MC.E).

Na Alemanha e no Brasil, vivem-se agora dilemas da 'localização industrial', dependentes da capacidade de inovação existente, bem como das proporçoes dos novos ramos industriais. A nova técnica exige, ademais, um grande número de especialistas de elevado nivel, fornecidos por escolas, ginásios, escolas técnicas, escolas técnicas superiores e universidades. Elas formam una instituição social, encontrando-se em relações e divisão de trabalho internas umas com as outras. Tal instituição promove múltiplos processos de inovação social, como especialização, pesquisa, definição de pesquisas em cooperação com a grande indústria e institutos de pesquisas, ou cm cooperação com as pequenas e médias empresas (PME), ou em responsabilidade própria, quando não existem outros pretendentes a parceiros sociais. Das universidades são exigidas importantes funçôes sociais, que lembram seu nascimento, isto é, lembram a 'idéia' de universidade c sua autononia irrestrita, ao menos na perspectiva das universidade européias ocidentais.

O conceito de inovação compreende os lados material e social do uso e da incorporação das tecnologias. Inovações relacionam-se à 
produtividade do trabalho, ao processo de produção e aos próprios materiais, sempre articulando, nesta particularização, as respectivas relaçóes ou circunstâncias nacionais e internacionais das novidades tecnológicas. $\Lambda$ regulação keynesiana clássica referencioulse até os anos setenta, primariamente, à elevação da produtividade do trabalho para, através da redução da jornada de trabalho, criar ou manter postos de trabalho. As novas tecnologias nas áreas da eletrônica e informática estimularam inovaçoes de processos, produtos e técnicas nos novos tempos, que repercutiram na organização interna de fábricas e escritórios, tendo influência nas mudanças de qualificação c na combinação das velhas hierarquias ua área da gerência tecnológica.

Estas inovações acabaram desencadeando uma revolução nas exigências de qualificação e naquelas definịçoes profissionais simultaneamente cerceadas, mudando radicalmente procedimentos de administração e organização. Nestas condiçoes, pode-se dizer que estas inovaçóes de técnicas e processos, que naturalmente sempre retroagem na produtividade do trabalho, desencadearam uma 'revolução', que simultaneamente afetaram ensino e pesquisa, administração è gerência, assim como, a organização interna das fábricas e a administração. Dessa forma, o desenvolvimento da universidade é mudado basicamentes.

A pesquisa universitária permanece parte importante destas inovaçóes. Contudo, ela fica estreitamente acoplada, tanto ao conhecimento básico, às aplicaçóes e ao desenvolvimento, quanto às respectivas mudanças nas diferentes formas fabris. Estas interconexóes foram discutidas no passado, sobretudo por J. Schumpeter, que as apresentou de tal mancira, que a universidade ficou simplesmente como pressuposto da descoberta e da inovação, enquanto

"KAMIEN, M. I., SCHWARZ, N. L., Technology, More for Less", in WEINTRAUIB, S. (ed.), Modern Eronomic Thoughl, Oxford, 1977. STAUDT, E., Das Managemem von Inovotionen, Frankfurt, 1986. SPAETH, L., Wende in die Zukunft, Reinbeck bci Hamburg, 1985. ZAPF, W, Ueber sociale lmovatimen, in Sociale Welt, Heft 1,2, 40jg; SCHROEDER, K.; FUHRMANN, I: U.; HERING, W., Wissens- und Techrologie- trams/er, Berlin, 199 \&. SCHROEDER, K. u.a., Wissens- und Techmologietrans/er ans wniversitaerer Sichl. Ergebnis einer Befragung universitaerer Hochschullelbrer, Berlin, 1991. 
os empresários ousados, que quiseram reforçar suas vantagens nos mercados, tomaram as inovaçôes como meios de realização de lucros extraordinários. $\Lambda$ s novas tecnologias amadurcceram-se comercialmente, mantendo inventores e engenheiros sob supervisão on cooperação de empresários empreendedores, que, em geral, náa possuím qualquer formação universitária. A incorporação das novas tecuologias pelas pequenas e médias empresas pos cm xeque a tese schumpeterima da Inovação, segundo a qual, às grandes fábricas monopolicas serian dadas as molhores chances de incorporarem as novas tecnologias.

$\Lambda$ importancia das novas tecnologias éa possibilidade do seu uso monopólico obrigaran as grandes fabricas a possuŕrem suas próprias equipes de pesquisas, que se diferenciavam das pesquisas das universidades por sua proximidade aos problemas e objetivos produtivos, orientando, por conseguinte, suas pesquisas para a prática. Tais fábricas puderam financiar pesquisas direcionadas objetivamente, assegurando-sc mesmo dos insucessos, isto ć, tambén utilizando-as em seus múltiplos pacotes produtivos. Os altos salários fizeram com que os melhores cicntistas preferissem estas fábricas monopólicas. Os aspectos negativos vieram da estrutura burocrática das fábricas, da rigidez. da gestão e da pouca flexibilidade destas grandes empresas, assim como da unilateralidade dos pontos críticos da produção e do enveHhecinento dos gestores a do pessoal especializado. Dependeria da atualidade da tecolologia e da fábrica, se a pesquisa exerceria influência direta nas inovaçóes.

Até os anos sessenta, não há dúvida que as grandes empresas monopólicas tiveram suas vantagens na valorizaçáo da tecnologia e na sua transformaçáo inovadora. Desde esta época, tais relaçóes giraram a favor das pequenas e médias cmpresas, para as quais as pesquisas nas universidades comecaram a favorecer. Com isso, passa a existir um referencial dinanico das grandes para com as pequenas cmpresas. $A$ tese schumpeteriana de favorecimento da grande empresa ć objetada na própria realidade, reafirmando a antiga tese de que os cmpresários propensos ao risco, que inovam tecnologicamente (que transformam novas tecnologias em inovaçóes), fazem- 
no náa en grandes empresas, scnão nas pequenas e médias".

Cada inovaçáo ten suas referencias internas e externas. As relaçōes externas, sobretudo, recebem suas influências das diferentes regulamentaçócs estatais da tributação e da política conônica en geral. Elas têm acolhida nas discussões, elaboraçōes e nas políticas de interesses de associaçōes, sindicatos e empresas, referindo-se relativamente à ciência e à universidade, que roma os incentivos c descobertas do exterior e tradu\% em pesquisas próprias. Os estágios das pesquisas e dos interesses, e também as novidades tecnológicas, são colocados à disposiça através dos chanados "meios de impulso': exposiçoes, literatura especializada, teiras, congressos, leis, patentes, etc. Aqui, a miversidade ainda movimenta-se no quadro clássico da politica $\bullet$ da representação de interesses, cm que cla gera suas contribuicóes cxatas e definidas nas pesquisas e nas ciências.

Contudo, nos novos tempos, o papel especial da universidade torna-se mais visivel. Isso porqune as grandes empresas monopólicas incorporam as inovaçoes externas e internas muito limitadamente ce as associaçeses es ministérios, influenciados por elas, tomam conbecimento da força potencial das novas inovaçoes, apenas condicionalmente. As razóes parecem ser yue as forças de ponta perderam a amplitude de visão ou tiveram envelhecidos seus conhecimentos, subsistindo resistências mentais ou estruturais internas ä inovaçäo, ou cutão, que o proesso decisório das empresas perderam en agilidade. Na política, isto aparece sob a forma de que os altos funcionários cos servidores públicos sc impregnann de crescentes diletantismo e também carreirismo. Mas, também os pequenos e medios empresários, que teriam a capacidade intelectual e empresarial para reagir as novidades tccnológicas, estão sem espaço de movimento, porque a situação e os custos não thes deixam espaços, lhes faltam informações, os conhecimcntos são milate-

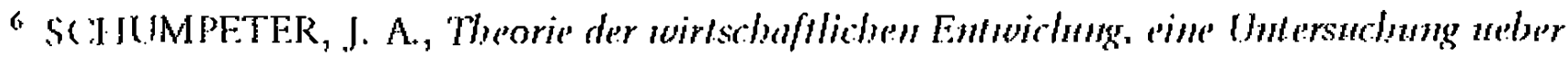

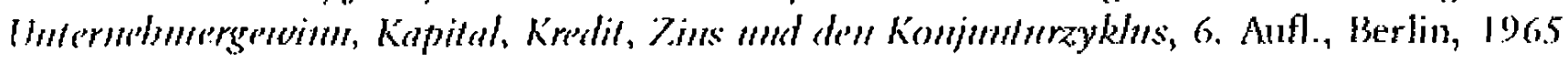

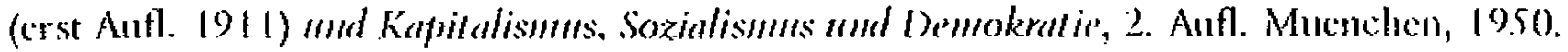

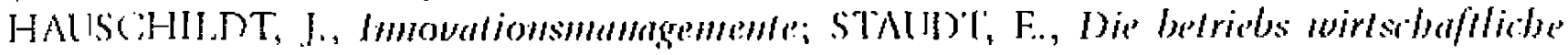

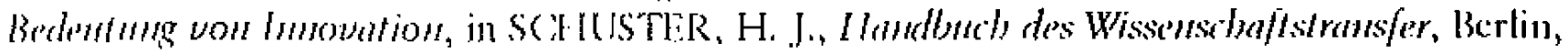
Heideberg et al., 1990. 
rais, lhes faltam capital ou prevalecem as inseguranças acerca da evolu(̧ão) dos mercados?.

Na Alemanha, as pequenas e médias empresas, na árca da cletrônica e da informática, ganharam um novo espaço e relativizaram parcialmente o papel da grande empresa monopólica. Cerca de $60 \%$ dos ocupados trabalham nestas pequenas e médias formas de empresas. Estas empresas articularam, nas associações e no interior da hierarquia estatal, crescentes interesses e formaram uma grande fração no interior dos partidos conscrvadores, (C)U, CSU e FDP. São-lhes atribuídas rápidas reaçôes às oscilações de mercados e à introdução de novas tecnologias e, por outro lado, a pequena burocracia em seu interior permite-se correr riscos náo admitidos $\mathrm{cm}$ grandes cmpresas. Nesse contexto, agem especialistas c solitários. As comunicações informais facilitam decisóes. Contudo, há frequientemente problemas com financiamento e insuficiências na avaliação das pesquisas básicas e suas tendências imanentes.

Nestes contextos, seria o caso de se chamar o Estado, isto é, governos regionais, para apoiar tais empresas, também podendo a universidade assumir seu papel especial. Existem claramente em cada região relaçóes objetivas entre as carrciras universitárias e as novas, pequenas e médias empresas. Está claro também que não são demandados, da universidade, as clássicas carreiras de ensino c pesquisa de economia nacional ou empresarial, de engenharias e ciências naturais ou de sociologia, não demandando, muito menos, as empresas tradicionais dos velhos ramos industriais, como têxtil, couro, construção civil, metalurgia, senão empresas modernas que sc desenvolveram em 'nichos estratégicos', orientadas tecnologicamente, como eletrônica, laser, bioquímica c biotecnologia. À elas correspondem somente cien-

7 SCHMALHOLIZ, H.; SCHOLZ, L., Imovationen in der Industrie, Straktur und Entrvicklung der Imovationsaklivilaeten, 1979-1982, Muenchen, 1989, und Sind kleine oder grosse Umernelmen imovationsfreudiger? Ergebmisse enpirischer Untersuchungen und slatischer Tests, in WEI ILIG, H. G., lmovation, cd. Landeszentrale fuer politische Bildung, Baden- Wiertenberg, Stuttgart, Berlin, Koeln, 1989. SCIIROEDER, K. 11.a., Wissens-und Tecbnologietrans/ler aus whiversilaerer Sicht. Ergebmis einer Befragung universitgerer Hodschullebrer, Berlin, 1991. 
tistas, que desenvolveram tais tecnologias e ramos do conbecimento, estendendo tais conhecimentos para a organização interna, estratégias de mercados, ocupação, política e marketing. É numa cooperação desta forma que, sem dúvida, torna-se possível o trabalho produtivo, a pesquisa e o consino".

\section{ESCOLAS SUPERIORES E TRANSFERẼNCIAS DE PESQUISAS}

A transferencia de pesquisas não deve ser comprecndida como rclaçóes soltas de professores com os agentes estatais ou empresariais, senăo como entrelaçamento sistêmico entre diferentes instituições en diferentes níveis sociais. As conexóes usuais são estabelecidas entre pesquisa c ensino e não entre a lógica imanente de pesquisa e exereicio ou prática. Isto significa que as universidades devem se movimentar do amplo espectro das pesquisas básicas e da independência da ciencia para o plancjamento da pesquisa, bem como da sua transferência c, mais além das concessoes, deve perseguir tarefas determinadas".

Numa forma de transição para novas determinaçóes funcionais de ciência e universidade, nos anos setenta e oitenta, governos estaduais, municipais e escolas superiores esforçaram-se em constituir os 'pólos de desenvolvimento' ou 'pólos tecnológicos', voltados para di- fundir informaçóes especializadas, e também para incentivar projetos llas universidades e motivar os empresários para determinados desafios is universidades. Além disso, alguns estados da federação tomaram a iniciativa de estabelecer não somente programas de pontos crí-

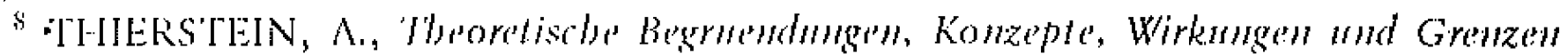

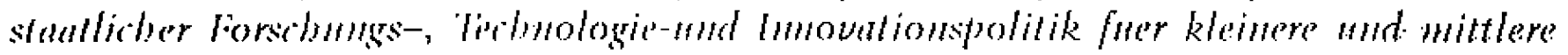
Un!remelmmen. Dissertation der Hochschule St. Cahlen, Bamberg, 1988. SUESS, W, SCHROLIOL:R, K., Tedmik mil Tmkum/l, Opladen, 1988. ROTHWELL, R., Jmer-Firm Relationship and Terdmological Change', in Entrepreneurship and Regional Developmem, Londres, 1989.

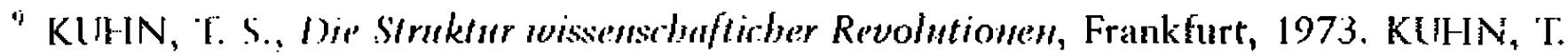
S.; KRUl[GilR, L. v. (ed.), Die Ensielung des Nemen, lrankfurt 1978. OEHLER, Ch.,

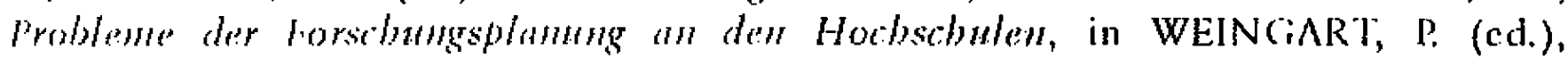

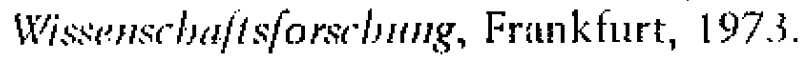


ticos para o fomento das inovações de tecnologias chaves, mas também objetivos da política de pesquisas. Todas estas iniciativas se deram num quadro de novas tecnologias e processos. () sentido delas foi motivar as universidades a se esforçarem por pesquisas e projetos de pesquisas, concorrendo umas contra outras.

Com isso, o 'processo de inovação' da economia deveria ser acelerado, devendo lucrar, sobretudo, as pequenas e médias empresas. Ademais, imaginava-se que as universidades se engrenariam fortemente com suas regiōes, preocupando-se com a substituição dos 'velhos' ramos industriais, que migravam ou fechavam, pela instalação de novas e exitosas firmas. Pensava-se também, através destas medidas, melhorar as chances de trabalho dos profissionais universitarios e dos pesquisadores cientistas profissionais, possibilitando a aproximação de diferentes grupos de interesses por meio das escolas superiores ou dos postos de cooperação. Uma tal 'abertura' da universidade viria a desencadear, de acordo com o pensamento dos planejadores, tanbém sua reforma e mudança internas ${ }^{10}$.

As verbas de pesquisas do governo federal alemáo foram elevadas. Anualmente foram investidos e distribuidos cerca de DM $\$ 50$ bithóes. A maior parte foi destinada à instituiçôes de pesquisas das grandes e monopólicas empresas. Um terço destes recursos foram para as escolas superiores, isto é, para institutos de pesquisas independentes. Só esta distribuç̧ão de recursos das autoridades federais já sinalizava que se confiava no maior sucesso e relevância da pesquisa da grande indústria. E, que estaria garantida a possibilidade para as universidades se adaptarem às exigências da reorientação tecnológica da economia industrial, movendo-se em torno da questão da localização e do nível da produção'".

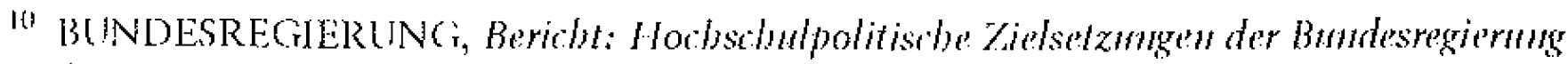
and Foerderwing der Driftmittolforschming, Bonn, 1995. BUNDESMINISTER FULR FORSCHUNG IND TECHNOLOGIE, Bundesberich Forshmis 1984, Bonn, 1984.

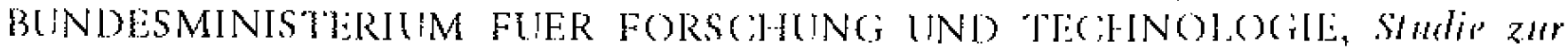

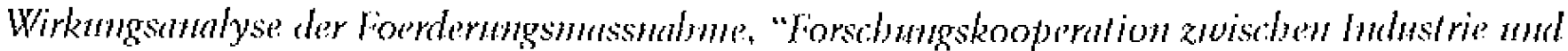
Wisesed aft", Bomn, 1987.

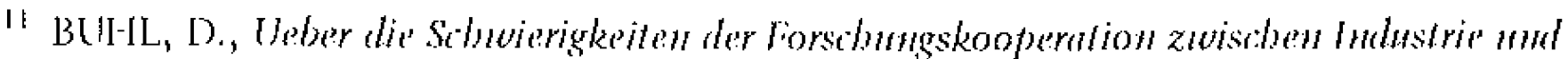


Com isso, os rumos das mudanças na estrutura da universidade foram indicados. Até então, as pesquisas básicas haviam sido independentes e referenciadas à sua própria lógica, isto ć, comunicavam-se com os resultados a tendências mundiais destas mesmas pesquisas. Agora, passaram a ser erigidos os quadros de referências, as exigências c as finalidades. Com isso, ficon claro que a liberdade de ensino e pesquisa ficaria sob a pressão de necessidades sociais, que os tempos de ruptura políticos e técnicos acusariam. $\Lambda$ pesar da autonomia universitária constitucional na Alemanha, a universidade está submetida como 'grande (mopresa' a una socializaçăo que se manifesta na pesquisa, sobretudo no ensino. $\grave{\Lambda}$ transferencia de pesquisa submetem-se năo somente empresas, governos ou 'critérios de racionalização', mas tambén a própria universidade é carregada numa associação de instituçcos c corporaçoes, que são obrigadas a cooperarem entre si. Racionalização e institucionalização serão diferentes nas ciências cconómicas e sociais, nas ciências naturais c nas engenharias ${ }^{12}$.

\section{A UNIVERSIDADE DO FUTURO E SUA REFERÊNCIA}

COM O DESENVOLVIMENTO SOCIAL.

Todas as analises e prognósticos sobre a transferência de tecnologia e de conhecinento indicam daramente que as universidades modernas se cncontram num processo de mudança fundamental. Nesse caso, é sinalizado cue somente as especialidades abertas às inovaçōes estarian en condiçós de se adaptarem a tal processo e suas exigências sociais, enquanto as ontras especialidades envelhecidas, tornarse-iam inuteis ( contraprodutivas. Isto nâo se aplica tanto às ciências naturais, mas sobretudo, as ciências sociais c humanas, desde que náo participem da formação dos novos protessores e suas especializaçoes.

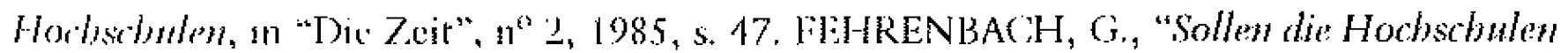
z" Unerableihugen der Industrie werdent", in l'rankfurter Rundschau, von 18.12.1984.

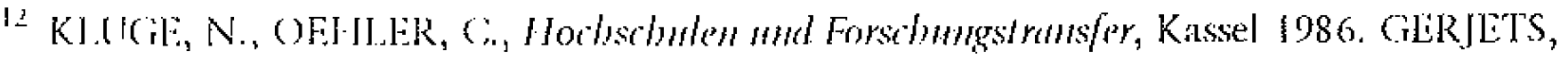

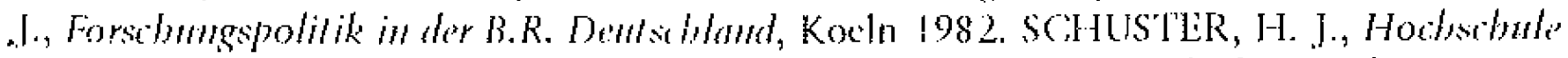

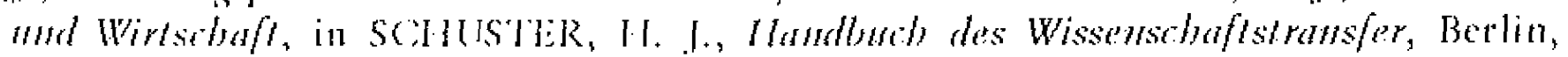
lacidelberg, 1990. 
Algumas carreiras da cconomia, das ciências políticas, da filosofia e da sociologia perdem seus lugares tradicionais de críticos deste processo de mudanças, não podendo participar nem transportar ou alavancar, com suas colocaçóes, as novas questóes decorrentes deste processo. Com isso, estas novas orientações na universidade provocam um processo de cisão organizacional e acadêmica das universidades, entre áreas hábeis às inovações e as inábeis, improdutivas, que se distinguem imediatamente entre participação ou não nos vínculos sociais com financiamentos, encargos e capacidades de pesquisa, ensino e poder ${ }^{13}$.

Para poderem manter esta posição de intermediação entre as múltiplas exigências sociais e a capacitação de cientistas profissionais úteis, as universidades são obrigadas a ampliar as bases das pesquisas, bem como promover o trabalho interdisciplinar. Somente assim, pode-se garantir o debate entre cientistas e intelectuais oficiais de todos matizes e as novas geraçós. Nesta tensão, agem pesquisa e ensino, adquirindo novo impulso na atualidade.

As necessidades de qualificação não decrescerão no futuro, ao contrário, crescerāo ainda mais, aparecendo aí problemas com o recrutamento dos novos professores e do pessoal técnico-cientifico na economia e na administração, pois as mudanças no cnsino e pesquisa nas universidades exigem novos conhecimentos técnicos e científicos, que somente com novo pessoal poderão ser cobertos. Estes novos deslocamentos tecnológicos, em quase todas as áreas sociais, compreendem cerca de $60 \%$ das profissóes científicas, elevando, portanto, as necessidades de qualificação. Deve-se acrescentar que na Alemanha e no Brasil a estrutura de idade é desfavorável. Somente cerca de $30 \%$ do pessoal especializado abaixo dos 50 anos alcançaram posiçoes de rclevo nas miversidades e na economia. Ao mesmo tempo, o número de estudantes do secundário e das escolas superiores tende a cair em cerca de $40 \%$. Dessa forma, a tendência é que estarão disponíveis mais alternativas profissio-

13 BOURDIEU, P., Homo Academicus, Trankfurt, 1988, s. 100, 119, 213 e 259. 
nais simultaneamente à redução do pessoal acadêmico ${ }^{14}$.

Através da integração de diferentes mercados na Europa Ocidental, América do Norte e do Sul e da crescente concorrência, exatamente na área tecnológica, as escolas superiores estão obrigadas a reagir numa tripla direção. Elas precisam reforçar a cooperaçâo in terna entre as areas especializadas. O trabalho conjunto (parcerias) entre universidades tensionadas precisa adquirir novas formas. $O$ plano regional das relaçôes entre universidade e economia precisa ser reforçado. Daí resultam novos perfis de qualificaçāo, que primarianente devem ser incluídos nas universidades.

Mas estas exigências não estão postas apenas para as universidades. Também os empresários precisam compreender que o fator de educação social - universidade - facilita trabalhos de pesquisas, de recstruturação, e, principalnente, de viabilização (racionalização). Da mesma forma, deve ser dito que a política educacional do Estado e dos partidos devem apoiar esta realocação produtiva das universidades, nâo colocando-as sob riscos através de cortes financeiros ou intromissão irracional nos seus assuntos. Através de mudanças das leis c diretrizes das escolas superiores, o governo federal pode conceder novas liberdades para as universidades ${ }^{15}$.

A universidade do futuro terá por caraterística, por conseguintc, que as pesquisas básicas scguirão menos a orientação de ciências puras, adquirindo mais significado as relaçôes recíprocas entre ciências aplicadas e técnicas, organização, invenção e ambiente. A distância entre trabalho científico e sua aplicação torna-se menor. As esco-

14 ALLESCH, J; NMANN, R; PREISS - ALLESCH, Wissenschafts - whd Technologie frahsfer an don Horbschulen, TU - Dokumentation, Heft 25, Berlin 1984. SCHUSTER, I-I. J., Hodbshule whd Wirtsdafl, in SCHUSTER, I-I. J., Handbuch des Wissenschaftstransfer, Berlin, Heidelberg, 1990.

15 BUNDESMINISTERIIM FIER FORSCIUNG UND TECHNOLOGIE, Studio zur

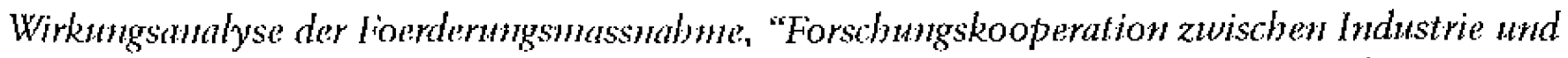
Wissesclaft", Bonn, 1987. BUNDESREGIERUNG, Bericht zur Foerderung der Drittwitlelforschung im Rabmen der Grundlagenforschung, Bundesdrucksache 10/225. SCHUSTER, H. I., Hochschulc und Wirtschaft, in SCHUSTER, H. I., Hondbuch des Wissenschaftstrans/er, Berlit, Heidelberg, 1990. 
las superiores não estão somente compelidas para a cconomia, ao serviço público, à região e às relaçóes sociais, mas também, para o estabelecimento de novas relacóes com a pesquisa e o ensino. Objetivos profissionais c definiçóes de novas profissóes acadênicas encontrantse em mudanças. Transformaçóes semellantes experinentam também as relaçōes internas entre responsaveis do corpo de docentes e categorias do estudantado. Todas as especialidades tornam-se otimistas da inovação e da cooperação, desenvolvendo críticas aos velhos reforenciais, às velhas visóes e à petrificaçáo dos conservadores - deles só recentemente separados - que se opoem a aceleração da 'economização', racionalização ou estatizaçăo, isto é, a socialização da universidade, anunciando precançōes. A universidade do futuro é, evidentemente uma formação em processo, cujo formato final ainda não foi encontrado.

Na Mlemanha, cla se processa num quadro estatal de leis de diretrizes das escolas superiores, de nedidas organentárias c de disposiçōes financeiras. Primariamente, o Ministério para (jência c Pesquisa c o Ministério de Economia influcnciam os pontos críticos da pesquisa e das linhas de pesquisas. Ao lado do Estado, a economia privada coloca à disposição a maior parte dos recursos para pesquisas, podendo estabelecer os objetivos das linhas de pesquisas, através de seus próprios institutos de pesquisas, e de contratos de cooperaçáo com institutos nuversitários, departamentos e a própria administração. Neste contexto, também atua a Comunidade da Pesquisa Nlená (DFG), que por iniciativa própria estabelece princípios e remas de pesquisas, os quais sáo escolhidos por amplos comitês de pareceristas que se organiza numa espécic de autogestão da commidade cientifica e pesquisadora. Apesar da amplitude dos tenas, a DFG precisa dar espaço as correntes da época, procurando satisfazer a política científica do governo federal.

Além disso, existe também ma série de fundaçōes públicas e privadas que incentivam e apoian as pesquisas e os trabalhos cientíticos dos cientistas profissionais. No geral, pode-se dizer que as "pesquisas de inovaçóes" são produtos c fundamentos do desenvolvimento tecnológico, razôes pelas quais o Estado e a economia devem estabe- 
lecer objetivos, qualidades e linhas de pesquisas, e, no caso da Alenanha, deve também assegurar a localização industrial, a ocupação dos fatores de produção da economia alemã e as exportações. A polírica de pesquisas assim determinada deixa pouco espaço para alternativas. Desta forma, a universidade do futuro traz a tendência de ser ainda mais estatizada (portanto, também politizada), trazendo para o ensino e a pesquisa as relaçōes de poder que conformarão a instituição, os grupos de pesquisadores e os professores que virão a ser privilegiados, apontando para os recursos de pesquisas e projetos que serão prioritariamente administrados.

Contra tais determinaçóes externas, a universidade tem ponco a apresentar. $\Lambda$ independência da universidade não mais se afirma através da administração própria de seus grêmios, pois Estado, partidos c associaçōes agem através do Conselho (urador ou do orçamento da universidade. Só os direitos estatutários dos professores e a garantia da manutenção mínima dos institutos e departamentos asseguram sua pouca autonomia. No geral, a universidade está compelida a apoiar, através de uma política científica e de pesquisa interna, a participação nos recursos de terceiros, mas também colocar à disposição recursos próprios para incentivar as pesquisas. Exemplarmente, o Departamento de Pesquisa da FU Berlim entende-se assim, como local de assessoramento e incentivo às pesquisas que servem Berlim.

Porém, também aqui as autoridades municipais têm possibilidades de múltiplas influências. De fato, por via da Comissão de Pesquisa, são administrados recursos na FU (cerca de 8 milhōes de marcos anuais), que são redistribuídos aos projetos (recursos para material e pessoal), a título de incentivar novos pedidos de recursos de terceiros para a pesquisa, ou então, para apoiar aqueles projetos já financiados externamente (na verdade, recursos de contrapartida da FU). Ademais, cada departamento possui un orçamento de pesquisa que é distribuído internamente para cada professor. Sem dizer que do orçamento da direção central também podem ser deslocados recursos para financiar projetos de curto prazo.

Via DFG e outras fontes de recursos de terceiros são constituídas áreas de pesquisas especiais, nas quais diferentes projetos, de di- 
ferentes departamentos trabalham conjuntamente. Estas pesquisas especiais pertencem à iniciativas das pesquisas consorciadas, que servem para estabelecer novos contatos c relaçóes, através dos quais o Estado, a universidade c a economia geran novas relaçoes e pontos crítico. Todas estas iniciativas e medidas devem levar a ciencia a se confrontar com as diferentes instituiçóes sociais, participando da socialização potencial da ciência e da pesquisa. Todos estes projetos de pesquisas, áreas especializadas c associaçóes, administrados autonomanentc, facilitam a penctração da divisão de trabalho nas universidades tradicionais, mas também satisfazem a colocação de pontos críticos e da política de pesquisa desde fora, agindo, assim, unilatcralmente ${ }^{16}$.

ESCOLAS SUPERIORES E INICIATIVAS EMPRESARIAIS REGIONAIS

A política de pesquisa na República Federal Nlemá é estabelecida tendo como referência as pesquisas de inovaçóes da grande indústria. (Com isso, o espaço regional ficon durante muito tempo desconsiderado. Nos anos setenta, a referĉncia regional entra no campo de visăo, e, significativamente, no momento em que também o significado das pequenas e médias empresas na economia nacional se torna visível. As inovaçoes tecnológicas na informática e eletronica e, simultancamente, a reestruturação da tecnologia e organização das empresas deram a perspectiva regional. No cutanto, foi muito dificil comprovar os interesses, motivos e pressupostos destas empresas, porque elas não deram nenhum ou muito pouco impulso para as pesquisas. Foram constituídos seminários, conferências, simpósios, feiras, lojas cicntíficas, postos de transferência de tecnologias, grêmios de consultorias, ete., para que cstabelecessem contatos com as empresas ou com as iniciativas regionais e postos administrativos estatais. Com isso, os proprios grupos de pesquisadores das universidades precisaram se reorganizar,

16 WLSTDEITSCHE REKTORENKONFTRENZ, Iin Zukun/l der Hochsr hulen, Bom, 1988. WISSENSCHAFTSRAT, Bericht weber Dritlmitel der Hochschulen (vorlaeufige Ergebnisse), 1970, 1975, 1980, 1985, Koeln, 1986. 
erigindo novas relaçóes para que tomassem conhecimento dos problcmas econômicos da regiáo.

Num estudo sobre os primeiros trabalhos de pesquisas regionalmente oricntados nas escolas superiores de Berlim, constatou-se que somente uma parte da universidade estava interessada por esta temática. No item "transferência de tecuologia c conhecimento da conomia regional", as especialidades simpáticas às inovaçoes foram as principais, como nos demais itens do estudo. $\mathrm{N}$ as especialidades, dominaram as ciências naturais, a medicina $e$ as ciências da engenharia, enquanto as ciências sociais e humanas foram insignificantes. Significativo foi também nesse estudo que as areas intensivas em pesquisas e exigentes de recursos de rerceiros nas universidades, estiveram motivadas e direcionadas para acompanhar a economia regional nas pesquisas. Os professores e dirigentes de projetos pesquisados engajaram-se indiretamente nos pleitos por uma nova estrutura das escolas superiores, que garantissc uma melhora das instalaçōes infra-estruturais básicas c uma redução dos encargos do ensino. Mostraram-sc tambem favoráveis ao fortalecimento da incorporação da pesquisa no ensino.

Ainda neste estudo sobre as perspectivas da integraçáo regional das universidades, o trabalho interdisciplinar foi saudado e também o fomento interno na universidade de grupos de pesquisas temporários para abordar determinados pontos críticos das pesquisas. $\mathrm{Na} \mathrm{Co}-$ operação de pesquisas (consorciamento), também foi aceito a conexão de Ministćrios, Estados, DFG, fundaçóes e empresas industriais, sem se questionar sobre dependência c unilateralidade de tal engajamento. No entanto, reconheceu-se que, neste contexto, a cooperaçáo con a grande compresa ocorre melhor que a cooperação con as pequenas e médias empresas. () estudo acentuou também que, primariamente, as autoridades e associaçóes tiveram grandes expectativas nos postos de transferências, mas, na realidade, estes foram produtivos apenas condicionalmente. Eles serviran, até cntão, primariamente, para que as iniciativas de pesquisas na universidade se reorientassem, enquanto o assessoramento das pequenas e médias empresas manti- 
veram-sc nas fronteiras. Thambém as consultorias e postos de apoio às inovaçōes técnicas regionais não tiveram um bom andamento ${ }^{17}$.

Diferentemente da pesquisa na grande indústria, onde os prohemas da inovação e da tecuologia na econonia dominam e retroagem na pesquisa da universidade, na transferência de tecolologia e no conhecimento regional, a universidade precisa tomar a iniciativa, organizando feiras, consultorias on postos de transferências para identificar-sc com os problemas da regiáo e com a problemática do empresariado. Além disso, o assessoramento e planejamento das inovaçoes mas medias empresas nostraram-se difíceis. Aí, a administraçio estatal precisa dar garantias financeiras. (Os projetos de pesquisas precisam suportar os custos das pesquisas e dos primeiros desenvolvincutos. Com isso, os projetos de pesquisas são cmpurrados para as iniciativas empresariais.

Assim, mostra-se no plano regional, na tensāo entre pesquisa universitária e iniciativa empresarial, que a universidade precisa inspirar freqüentenente tais iniciativas on colocá-las en marcha. A "não transparência' do mercado, problemas financeiros e limites de conhecimento especializados dividem os empresários neste ambiente. Uns colocam em marcha scu proprio 'espírito de descobridor', propenso aos riscos e ganham novos mercados, náo precisando para isto nem das inovaçóes, nem dos postos de assessoramento das universidades. Outros, apesar do apoio, nāo vāo para frente. Por isso, os postos de transferências, cm suas relaçóes com os financiadores públicos, são vistos mais como postos de alcance de subvençóes estatais. Com isso, tais centros cacm no descrédito, scndo caricaturados. Na verdade, no plano regional, há nuito as universidades vêm trombando nas fronteiras da inovação de pesquisas ${ }^{\natural}$.

17 SCITROEDLR, K. I.a., Wissems - and Tebnologietrats/er ans whiversilatrer Sicht. Ergebwis eimer Be/roghns wiversitaene Hodhschullehrer, Berlin, 1991.

Is STAUD'l, E., Tedmologie and Regionalpolitik der Laender: Vom Leislangs and Subventionoutbewerb, in List Forum, Bd. 14, 1987/1988. SCIUSTER, H. J., Hodsshule:

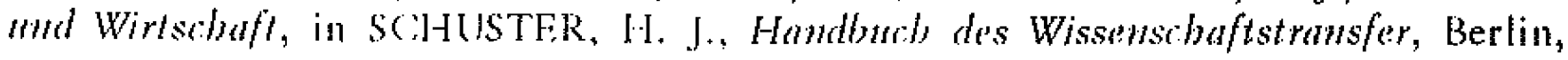
I.Icidelberg, 1990. 
Contudo, há iniciativas na miversidade vindas primariamente de áreas especializadas que ainda estāo fora da prática de pesquisa. Inquictaçoes políticas, originadas marginalmente nos partidos, associa̧ões, iniciativas civis ou movimentos sociais, são trazidas e trabalhadas cientificamente nas universidades. ('rítica social, isto é, inventários das conexôes sociais são aí apontados, ạtentando-se de que sejam apresentadas alternativas à lavagem cerebral consumista. Alguns temas relacionam-se ao radicalismo de direita, aos problemas da discriminacáo de diferentes grupos ou pessoas, as questóes do asilo político e ao desemprego ou a segmentaça social. Em resumo, os temas relacionam-se às contradiçoes e aos resultados da orientaçáo unilateral das inovaçōes teconológicas.

No contexto de tal forma de pesquisa, há iniciativas que não necessariamente desembocam em projetos de pesquisas, senão em apoios às árcas sociais, indo para muitos outros rumos. Por excmplo, podem destinar-se a iniciativas compresariais ou mesmo fundação de firmas, adquirindo múltiplas finalidades. Tais iniciativas buscam economizar conhecimento c congajamento, livando-se da proteçáo do estado social, isto á desvinculando-se da sociedade de formulários. $l$, chas estão empenhadas em oferecer oportunidades de trabalho aos estudantes que não se apresentam no morcado de trabalho normal. $\Lambda$ o mesmo tempo, são intermediadas experiências, são condicionadas as ascensôes profissionais nas suas novas atividades, ctc. Há frequïntemente cstreitas conexöes entre pesquisa e conomia. No entanto, aí nāo se trata tanto de inovaçóes tecnológicas, senão da abertura de novos campos para as profissōes acadênicas, para as quais cresec a demanda no mercado de trabalho. Estes projetos e empresas estorgam-se em superar as distâncias entre a capacitação c a definição profissional nas especialidades das ciências humanas, e também das ciências cconômicas.

A findação de firmas relaciona-se primariamente à firmas comerciais, pois aí o capital inicial é monor e a possibilidade de entrar nos vazios de mercado, maior. (ampanha do chá, alimentos naturais, construçôes ecológicas, café nicaragüense, ctc, são exemplos. São trazidos valores éticos, como justiça, solidariedade on engajamento que justificam a predisposiçăo aos riscos e mudanças de hábitos. Sobre tais 
atividades são definidas freqüentemente as novas profissōes. Estas firmas encerram atividades e novos mercados que estavam fora da prática das universidades. Elas sāo bem sucedidas, ali, onde as pesquisas de inovaçôes fracassaram nos locais de transferência tecnológica. Estas iniciativas são importantes complementos da pesquisa de inovação para a FU-Berlim, porque as especialidades, até entáo inativas, passam a ser exigidas e porque aí é estabelecido una razoável conexão entre pesquisa de projeto, projetos fomentados na área social e econonia (racionalização) de interesses específicos ${ }^{19}$.

\section{BiBLIOGRAFIA}

ALBUQUERQUE, Lynaldo C;; ROCHA NETO, Ivan, Estudo do Desequilibrio Econômico Inter-Regional, Tema: Ciêrncin. Tecmologia e Regionalizą̧̄o, Brasilia, 1994;

() Alruso Cientifico a Ternológico Brasiletro, CPI do Atraso Ternológico, Brasília, 1992;

Matriz de Compelência Técnico-Cientifica Nacional (Mimeo), Brasilia, 1992;

ALLESCH, J.; AMANN, R.; PREISS - ALLESCH, Wissenschafts - und Technolugie - transfer an den Hochschulen, TU-Dokumentation, Heft 25, Berlin, 1984;

AUMUELLER, U., Industrieschule and urspraengliche Akkumulation in Dentschland;

WENZEL, F, Sichernang von Massenloyalitaet und Qualification der Arbeitskralt als Autgabe der Volksschule, in NYSSEN, F. Waldeyer (Hg.), Schule und Stan im 18. und 19. Jahmhunderl, Frankfurt, 1974;

AZEVEDO, F. de, As Ciênitas no Brasil, Săo Paulo, 195.5;

BALTHAZAR, A.; SCARICABAROZZI, R., Modelos de Desenvolvimento Histórico das Cienncias Naturais nos Países da America Latina, 34: SBPC, Campinas, 1982;

BLANKERTZ, H., Bildung im Zeitaller der grossen Indhstrie, Hannover, 1969; BORDIEU, P., Homo Academicus, Frankfurt, 1988, s. 100, 149, 213 e 259;

1) SCARICABAROZZI, R. A., Universidad, Cioncia y Sociedad on América Latina, Buenos Aires, 1995. BALTHAZAR, A. e SCARICABAROZZI, R., Modelos de Desenolvimento Ihistórico das Ciencias Naturais nos Patses di América Latima, 34' SBPC, Campinas, 1982. XAVIER, 1. A., A Universidade no Nordeste, em A Comtonformeidale do Questäo Regiowh, Paraíba, 1992. 
BRANDAU, H., Die mitllere Bildung in Deutschland, Weinheim, 1959;

BUHL, D., Ueber dio Solnwigrigkeiten der Forschangskooperation zivishen Induslrie und Ho hschulen, in "Die Zeit", 11"2, 198.5, s. 47;

BUNDESMINISTER FUER BILDUN(' UNI) WISSENSCIIAFT, Zasammemambil ztoischen Hochschule und Wirlschafi, in Bildung-Wissenschafi - Akenell 6 , Bonn, 1985;

BUNDESMINISTER FUER FORSCHUNG UND TECHNOLOGIE, Bundesberibl Forsthung 1984, Bonn, 1984;

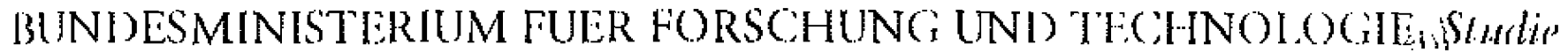

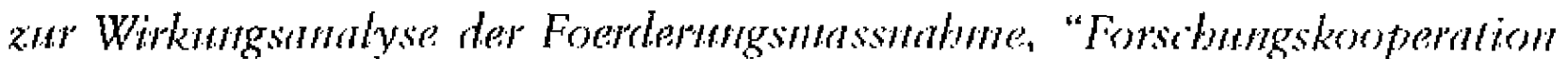
zioischen Industrie and Wisseschatt", Bomn, 1987;

BUNDESREGIERUNG, Berich zur Foenterning der Drilmiltelforshong im Rabmen der Gmmdlagen/orshming, Bundesdnucksache 10/22.5;

BUNDESREGIERUNG, Beribt: Hochsolmlpolitisthe Zielsetzungen der Bundesregianng whd Foerderung der Driumillelforschung, Bonn, 199.5;

(NPQ - CONSEL HO NACIONAL DE DIESENVOIVIMINIIO CIENTIFICO

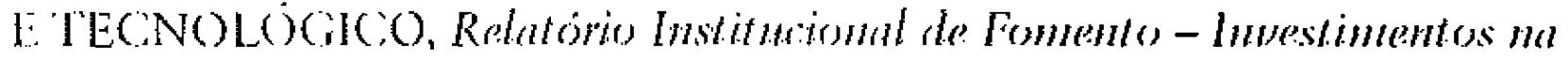

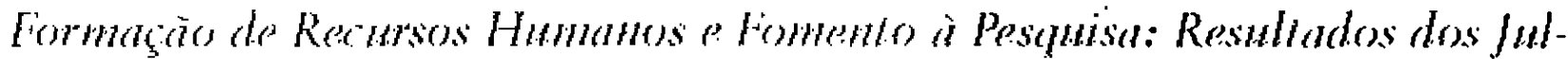
gamentos dos Comités Assessomes em 1990, Programas Básicrs, Brasilia, 1990

- Quem é Quem - Sistema um Linha de Aompanhamento de ProjeLos, Brasilia, 198.5

CUNIIA, L. A., A Unwersidade Tempont, Rio de Janciro, 1980; . A Universidade Crtica, Rio de lanciro, 1989

. A Universidadr Reformanda, Rio de Janeiro, 1989;

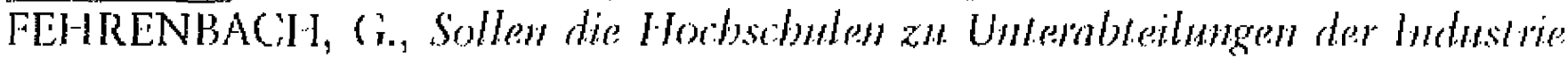
werden?, in Frankfurter Rundschath, von 18.12, 1984;

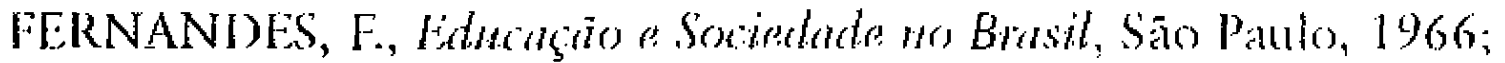

- Universidade Brasileira, Sãos Paulo, 1979;

FERRI, M. (.; MOTOYAMA. S., Hislónid das Ciênias no Brasil, São Paulo, 1979;

GERJETS, J., Forschnngspolitik in der B.R. Deutschland, Koeln, 1982;

HAUSCHILIT, I., Innowationsmanagemente; STAUDT, E., Die betriebs

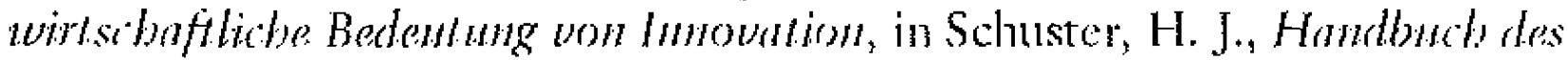
Wissenschaltstransfer, Berlin, Heideberg et al., 1990;

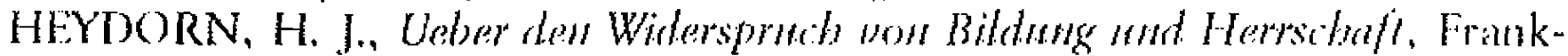
furt, 1979;

HUMBOLDT, W. v., Ideen zu einem Versub, die Grenzen der Wirksamkeil des Shautes za bestimmen, in Worke in fuenf Baenden, Bd. 5, Darmstadt, 1981; . Ines, Individumm and Shatsgeault, Leipzig, 198.5;

JAGUARIBE, H., Porque nõo se ba Desarollado la cientia en Am. Lanina, cn $\mathrm{S} \Lambda \mathrm{B} \Lambda \mathrm{T}(), \mathrm{J} .$, El Pensamiento Latimoamericano en la Problematioa Ciencia- 
leinologia, Desarollo y Dependemia, Buemos dires, 197.5;

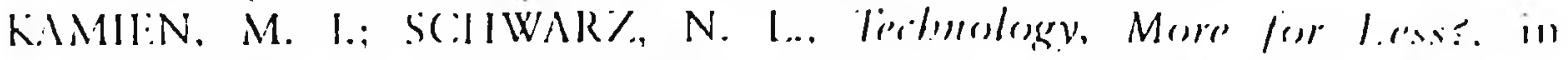

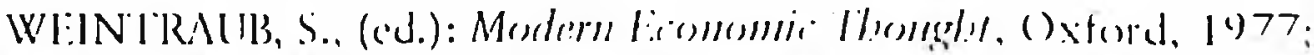

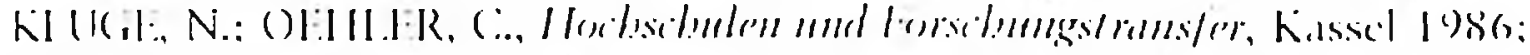

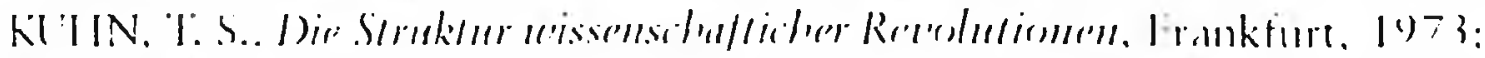

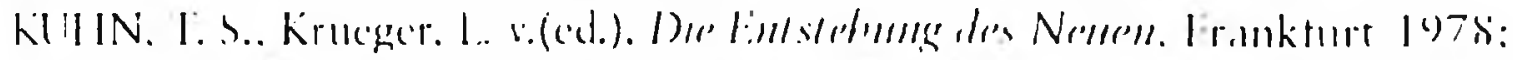

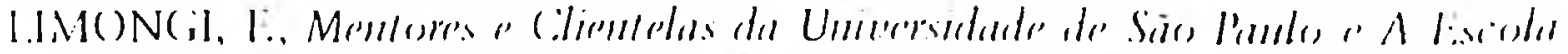

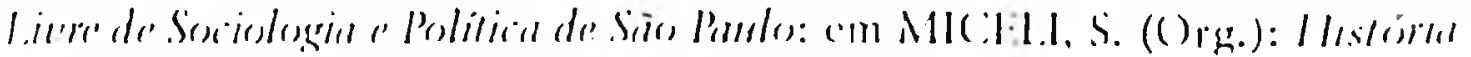

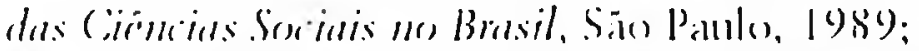

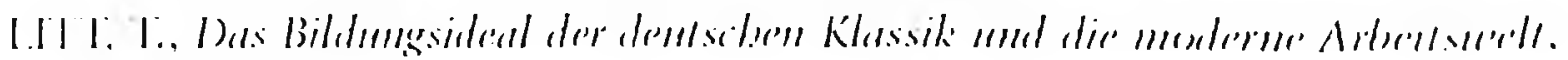
Bahlum (o. J.);

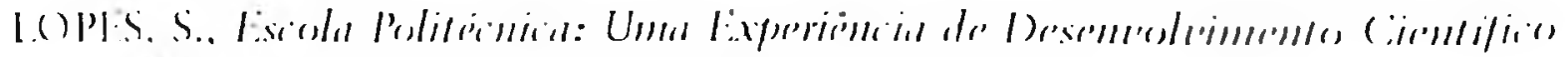

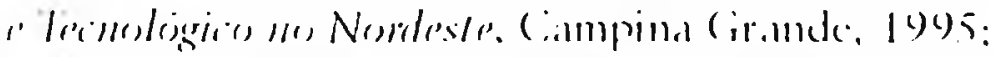

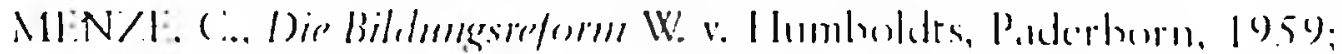

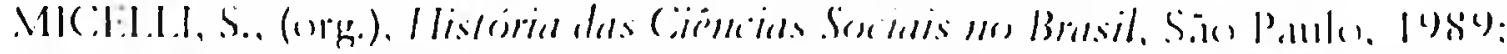

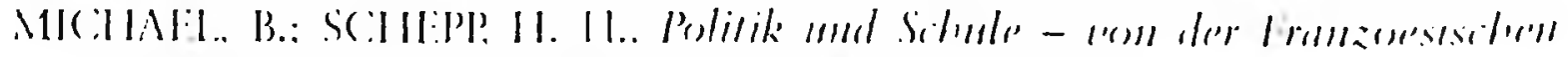

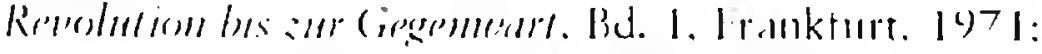

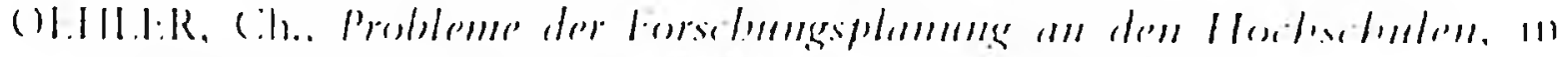
Weingart, P. (cd.): Wissenschaftsforschung, lrankturt. 197.3:

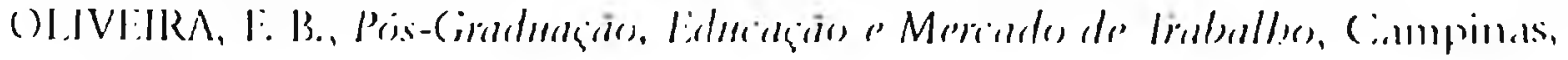
199.5;

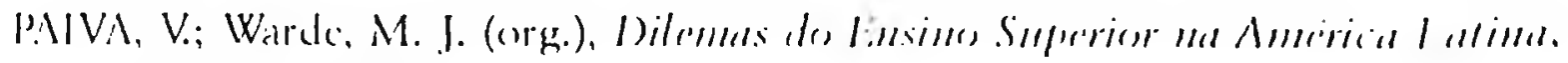
Cimpinas, 1904:

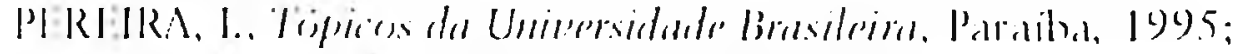

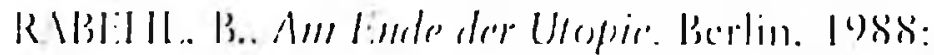

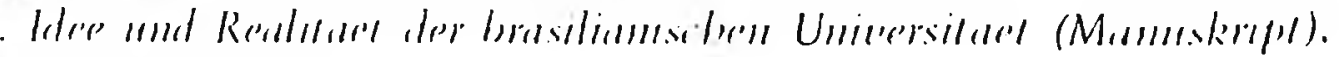

(impina (irande. 19)():

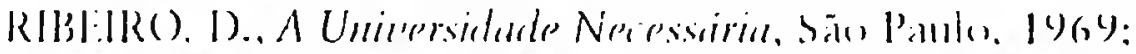

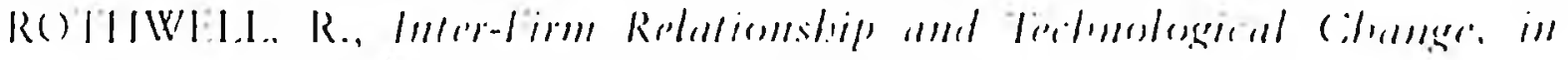

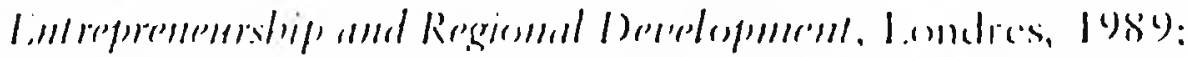

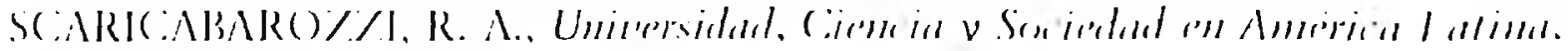
bucmos Aires, 1905;

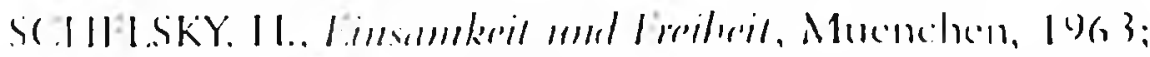

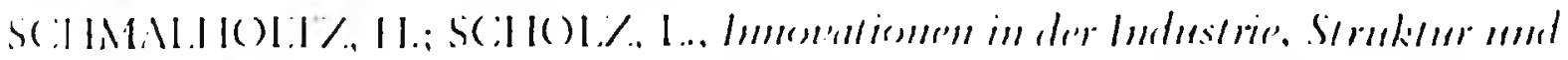

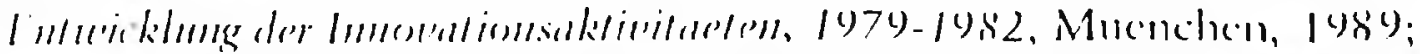

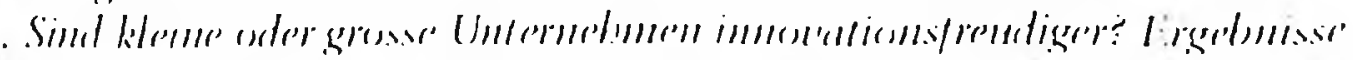

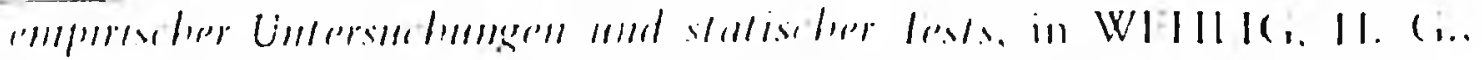

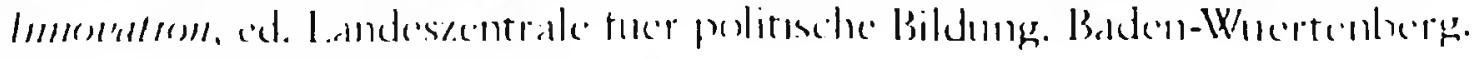
Stuttgart, Piorlin, Kowh, 1989;

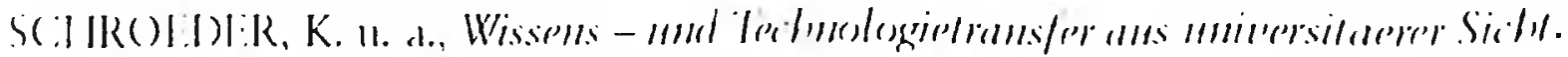

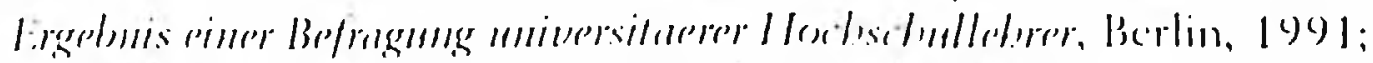

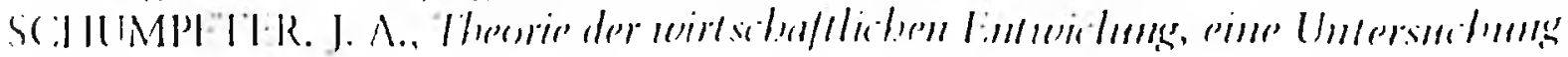




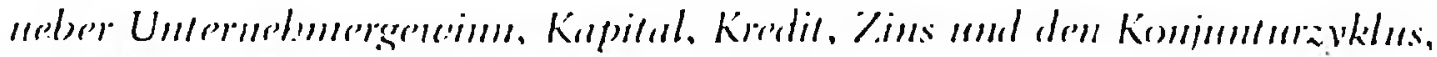
6. Aufl., Berlin. 1965 (crst Aufl. 1911): 1).5();

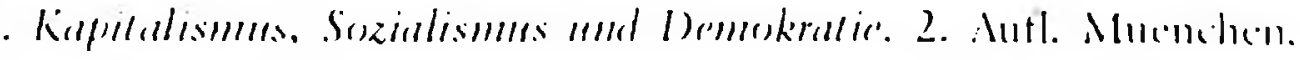

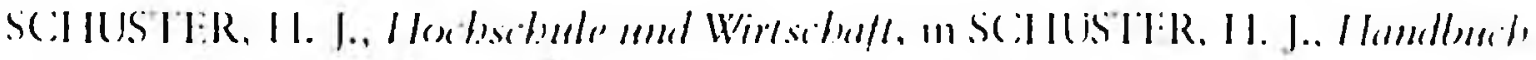
des Wissensibaflstrans/or, Berlin, Iledeldherg, 1990):

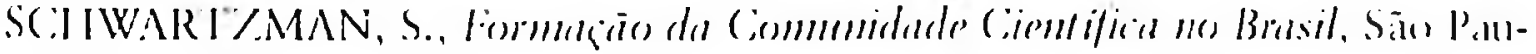
l(1, 1979;

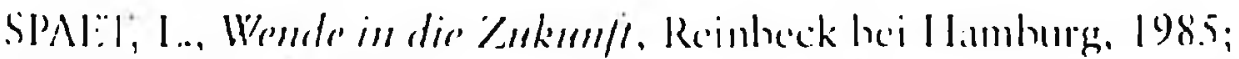

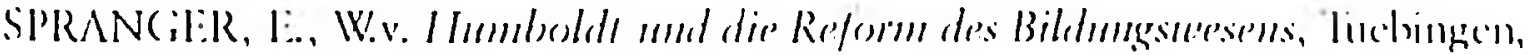
196()

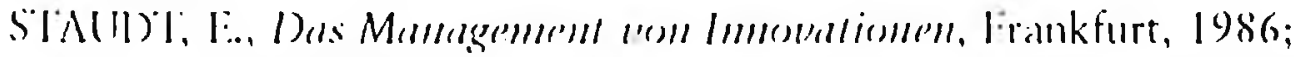

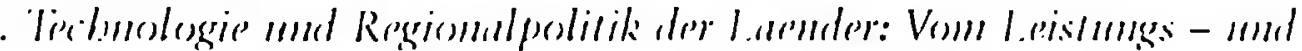

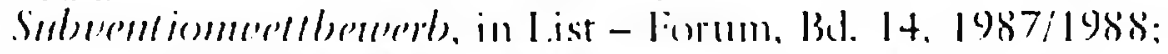

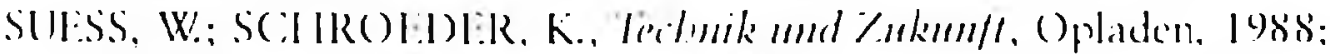

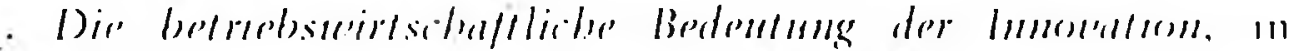

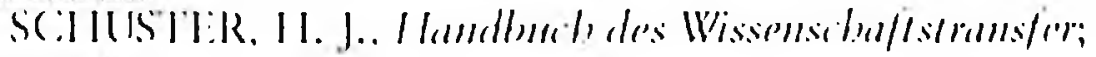

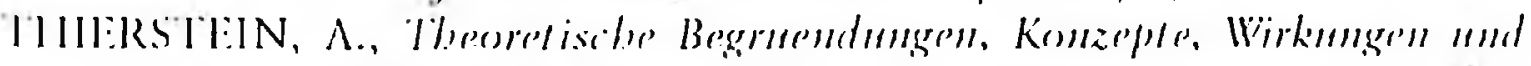

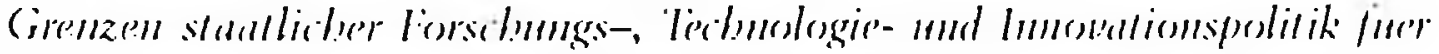

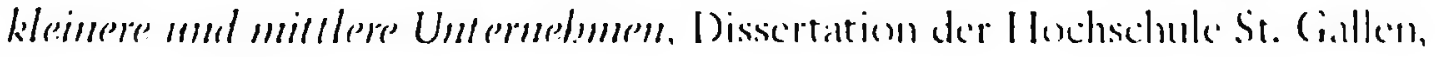
Bamberg, 198s;

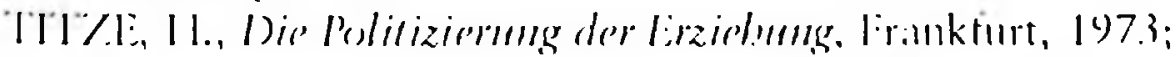

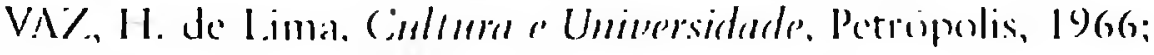

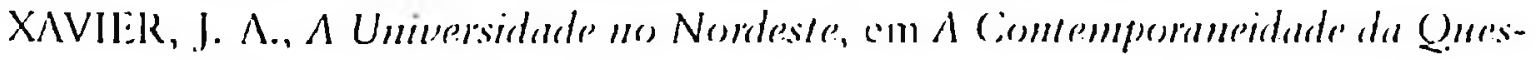
loio Regional. Paraiba, 1992:

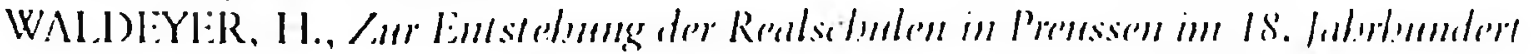

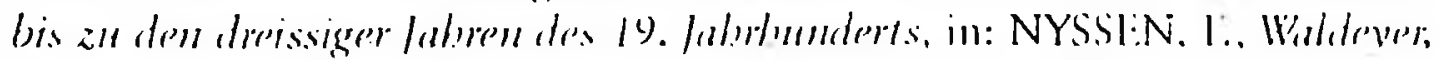

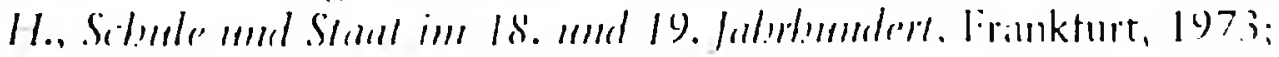

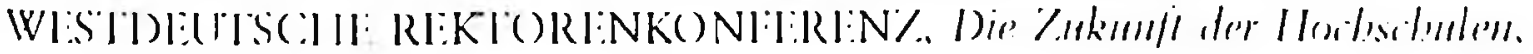
Bonn, 1988;

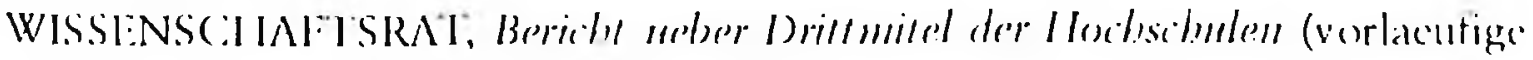
Figchuisse), 1970, 197.5, 1980, 198.5, Kochn, 1986;

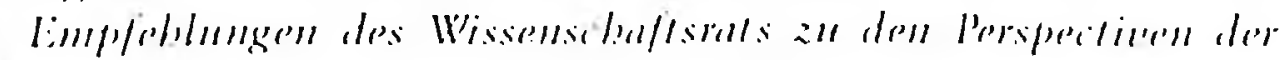

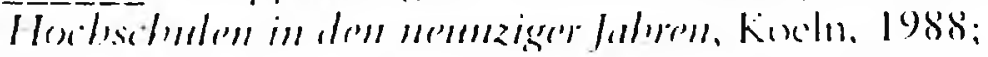

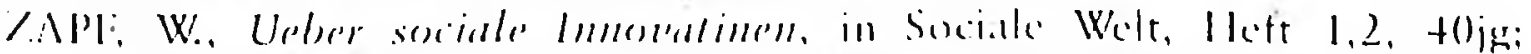

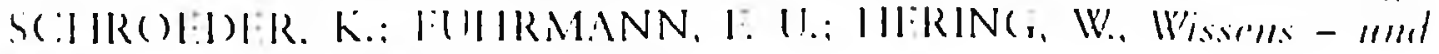

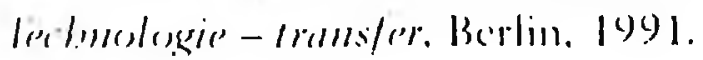

